DOI: 10.11606/issn.2318-8855.v7i7p187-207

\title{
O mundo medieval no Brasil do século XXI visto através da série de cartas colecionáveis Dracomania ${ }^{1}$
}

\author{
Giovanne Santos de Sousa*
}

Resumo: Este artigo tem como fim compreender a forma como elementos do mundo medieval e construções acerca deste, produzidos durante ou após o período, são valorizados e retomados na sociedade brasileira e no imaginário acerca do medievo, e como são materializados em obras iconográficas, e para tal se usará como fonte a série de cartas colecionáveis da Elma Chips intitulada Dracomania. Partindo dos estudos de Jacques Le Goff sobre o imaginário medieval e de José Rivair Macedo sobre os conceitos de "reminiscências medievais" ou "residualidades medievais" e "medievalidade", se buscará analisar como as cartas Dracomania são, por um lado, o resultado de um processo de revivalismo medieval, apresentando personagens que são representadas de acordo com uma Idade Média imaginada, com seres maravilhosos e humanos com aspectos sobrenaturais ou estereotipados, se encaixando no conceito de medievalidade e, por outro, são também o produto do imaginário medieval, criado e reproduzido por meio de suas lendas orais, obras literárias e criações artísticas e que sobreviveram e permanecem como fontes na atualidade.

Palavras-chave: Cartas Colecionáveis; Imaginário; Medievalidade; Revivalismo Medieval.

\section{Introdução}

Se a constituição de um campo de estudos sobre a Idade Média no Brasil é circundada

\footnotetext{
${ }^{1}$ Artigo escrito originalmente para a disciplina História Social da Arte ministrada pela Profa. Dra. Maria Cristina Correia L. Pereira no Departamento de História da Faculdade de Filosofia, Letras e Ciências Humanas da Universidade de São Paulo.

*Graduado em História pela Universidade de São Paulo. E-mail para contato: giovannesantos499@gmail.com.
} 


\section{artigos}

\section{Giovanne Santos de Sousa}

por uma série de questões que tangem à sua legitimidade e pertinência, sobretudo por parte de uma visão "produtivista" do saber que rechaça as ciências que não possuem uma finalidade mercadológica imediata e acolhem aquelas que buscam respostas para problemas práticos provenientes da necessidade de se produzir e acumular capital ${ }^{2}$, a acolhida da temática medieval em elementos da cultura brasileira se encontra em uma situação marcadamente diferente nestas primeiras décadas do século XXI.

Neste campo da mentalidade e de suas representações ${ }^{3}$, onde a presença da cultura medieval é evidente, há uma grande valorização da temática, que cresce de forma paralela à franca expansão dos estudos historiográficos medievais no Brasil (AMARAL, 2011, p. 448). Sem entrar no mérito dos elementos da sociedade brasileira que podem ser classificados como continuidades da Idade Média, tema tratado por Hilário Franco Jr. em seu ensaio "Raízes Medievais do Brasil" (FRANCO JÚNIOR 2008, p. 80-104) onde se afirma que, apesar de não haver uma Idade Média no Brasil, existe um "sistema de valores medievais" que influencia o comportamento coletivo brasileiro, o que se pretende aqui é levantar elementos para se buscar entender essa valorização do ideário medieval e de que forma o imaginário contemporâneo traz elementos deste período histórico e como eles são materializados por meio de representações iconográficas.

Com esta finalidade, diversas produções, sobretudo destinadas ao público jovem, poderiam ser analisadas de forma qualificada. Porém, tendo que os jogos e brincadeiras são construções virtuais humanas que, de forma geral, envolvem fatores socioculturais, e sendo a brincadeira, para o indivíduo, a porta de entrada em sua cultura; sua apropriação, no que tange ao panorama histórico-cultural (OTTATI; FREITAS FILHO, 2017, p. 151), acredita-se aqui

\footnotetext{
2 Esse argumento que associa as ciências humanas com algo que não contribui ao progresso material da sociedade e, no caso particular da história, que vê esta ciência como um estudo de um passado não mais presente e relevante é a base da recente reforma do ensino médio, que diminui as aulas obrigatórias de ciências humanas e da maior ênfase nas disciplinas consideradas mais úteis ao mercado de trabalho. É a base também para as iniciativas que propõem a retirada do ensino de história antiga e medieval das salas de aula.

${ }^{3}$ Seguem-se aqui as definições de "representação", "símbolo", "ideologia” e "imaginário" presentes no prefácio de Jacques Le Goff à primeira edição do livro "O Imaginário Medieval”.
} 


\section{artigos}

O mundo medieval no Brasil do século XXI visto através da série de cartas colecionáveis Dracomania

que manifestações lúdicas como jogos são fundamentais na construção do imaginário de um indivíduo e de sua coletividade e seu estudo tem grande importância para se compreender o modus operandi desta sociedade, portanto se analisará neste artigo a série de cartas colecionáveis Dracomania, que foi vendida na forma de brindes pela empresa Elma Chips em seus salgadinhos no Brasil no ano de 2008 e que, como será visto, representa de forma notável a materialização iconográfica do imaginário contemporâneo sobre a Idade Média.

\section{O Brasil e as Representações da Idade Média: Possibilidades de Análise}

Para se buscar compreender as razões que levam ao sucesso de produções contemporâneas com referências medievais, podemos partir de duas análises historiográficas não excludentes e complementares, que são os estudos sobre o imaginário ocidental acerca do mundo medieval realizados por Jacques Le Goff e a distinção feita por José Rivair Macedo entre "reminiscências medievais" ou "residualidades medievais" e "medievalidade".

Comecemos pelo historiador brasileiro. Macedo distingue as reminiscências medievais dos elementos representativos do que ele chama de "medievalidade". O primeiro termo se refere às produções medievais que chegaram aos dias de hoje parcial ou integralmente, constituindo, portanto, um grupo de construções humanas materiais ou imateriais produzidas em determinado contexto e com uma finalidade específica e que hoje, fora de seu contexto original, se apresenta como um vestígio daquela sociedade, como um documento. ${ }^{4}$ Como exemplo podem ser citadas festas populares como o carnaval, celebrações religiosas como as do natal e construções arquitetônicas como as grandes catedrais.

Diferente dessas reminiscências, os elementos que expressam a ideia de medievalidade, muito próximo ao que Umberto Eco chama de "Idade Média Sonhada", são aqueles que se utilizam da ideia construída, muitas vezes de forma estereotipada, do que foi

\footnotetext{
${ }^{4}$ Em seu artigo intitulado "Do Teatro da Memória ao Laboratório da História" Ulpiano Bezerra de Menezes demonstra como um artefato, transladado de seu contexto de produção, passa a ser visto como um suporte de informação, perdendo seu valor de uso e se tornando um documento (MENESES, 1994, p. 9-42).
} 


\section{artigos}

\section{Giovanne Santos de Sousa}

esse período, e não de documentos e vestígios da Idade Média. Este processo pode também ser comparado ao conceito de "Teatro da Memória", de Ulpiano Bezerra de Menezes, que trata da forma como artefatos de outros tempos e lugares são hoje expostos de forma a tentar recriar uma história, sem problematizações e reflexões acerca de seu contexto, sendo que no caso dos mitos e lendas medievais busca-se a recriação a partir de um passado que não existiu, como pode ser visto em livros, histórias em quadrinho, filmes, séries e jogos ${ }^{5}$, muito populares já no século XX e que permanecem com sucesso no século XXI.

Contudo, é importante observar que essa revisitação da Idade Média observada nos séculos $X X$ e XXI tem início ainda no XIX, no contexto romântico e nacionalista de busca de identidades nacionais e de idealização do passado medieval, quando no campo musical a ópera reforça cenários e seres da "Idade das Trevas" imaginada pelos renascentistas (LANGER, 2009, p. 3), na literatura autores como Willian Blake, Walter Scott, Victor Hugo, Alexandre Herculano, etc. retomam os temas medievais (OLIVEIRA; FREITAS FILHO, 2017, p. 143) e na área arquitetônica, com os início da noção de patrimônio cultural, intelectuais como o francês Viollet-le-Duc e o inglês John Ruskin passam a olhar as construções medievais como ricas obras de um período não mais visto como decadente (POBLADOR MUGA, 2014, p. 123). A essa retomada Jacques Le Goff vai dar o nome de "ressurreição romântica do imaginário medieval" (LE GOFF, 2009, p 89), que sucedeu o período onde

a herança dos mitos, heróis e maravilhas foi vítima de um esquecimento, de uma "perda" nos séculos XVII e XVIII, período no qual constituiu-se e reforçouse, do humanismo às Luzes, uma imagem "negra" da Idade Média: época de obscurantismo, mundo das trevas, dark ages (Ibid, p. 29).

Tratando das análises de Le Goff, pode-se explicar o sucesso da temática medieval no universo cultural contemporâneo como uma manifestação da continuidade do imaginário medieval no imaginário ocidental da atualidade. Por pertencer ao tempo das mentalidades, que é aquele tempo de longa duração, o que muda mais lentamente na evolução histórica, de

\footnotetext{
${ }^{5}$ As obras de Tolkien, criando línguas, seres e lugares que remetem ao estereótipo do que é o mundo medieval, é a grande fonte de referência de obras audiovisuais e jogos que seguem a temática.
} 


\section{artigos}

O mundo medieval no Brasil do século XXI visto através da série de cartas colecionáveis Dracomania

acordo com Fernand Braudel (Id, 1983, p. 188), as ideias, os mitos e as demais representações produzidas na Idade Média permanecem presentes na consciência coletiva com o passar dos séculos.

Em termos marxistas, o imaginário e suas representações fazem parte do campo das infraestruturas, aquele que demora a mudar, e não no das superestruturas, com rápidas modificações (LE GOFF, 1983, p. 246). Le Goff traz essa interpretação mostrando que é a partir da obra de J. Huizinga que a historiografia, sobretudo marxista, passa a compreender o mundo das representações como componente da categoria das infraestruturas, rompendo com a visão então consolidada de que ele estava exclusivamente no campo da ideologia, na superestrutura.

Esta continuidade, entretanto, não é linear e constante, havendo momentos de "eclipses e reflorescimentos", onde determinados elementos são ora esquecidos, ora retomados, gerando uma situação em que apesar de um mito, símbolo ou ideia ter sido deixado de lado, aparentemente esquecido, não significa que tenha desaparecido. O campo do imaginário é muito fértil e de constante renovação por meio de revivalismos, e a cada mudança social novos símbolos são criados e, principalmente, recriados, a ponto de se poder afirmar que "se existe uma história profundamente perpetuada e renovada pelas grandes ondas das revoluções do texto e da imagem, é realmente a história do imaginário" (Ibid, p.31).

As possibilidades de análise apresentadas por Jacques Le Goff e por José Rivair Macedo, portanto, apresentam compatibilidades na medida em que ambas explicam a existência de elementos medievais no imaginário contemporâneo atual por duas razões: a continuidade de eventos criados naquele contexto e existentes ainda hoje e a criação de novos elementos na atualidade com referências naquele período.

Aquilo que Macedo chama de "reminiscências medievais" no mundo contemporâneo são as representações do imaginário medieval que sobrevivem na atualidade. São a materialização das ideias e dos mitos da Idade Média que foram construídos com base nesse 


\section{artigos}

\section{Giovanne Santos de Sousa}

imaginário e serviram para alimentá-lo e reproduzi-lo, na época e nos dias de hoje, sendo que, se por uma lado essas fontes nos abrem possibilidades de análise histórica a partir dos elementos que sobreviveram, responsáveis pela continuidade das representações, por outro elas nos permitem criar novos universos a partir da forma como aquele período se imaginava, não se atendo às fronteiras do real e natural.

Este processo de criação foi aprofundado a partir do século XIX onde, não bastando imaginar aquele período tal qual o era pensado na época, o movimento de revivalismo medieval passou a criar um nova Idade Média, imaginada e não histórica, no que Macedo chama de medievalidade e que apresenta aspectos de criação, retomada e esquecimento constante de elementos específicos do imaginário.

As cartas Dracomania, tratadas neste trabalho, são o resultado desse processo do revivalismo medieval. Elas apresentam personagens que são representadas de acordo com essa Idade Média imaginada, com seres maravilhosos e humanos com aspectos sobrenaturais ou estereotipados, se encaixando no conceito de medievalidade. São também o produto do imaginário medieval, criado e reproduzido por meio de suas lendas orais, obras literárias e criações artísticas e que sobreviveram e permanecem como fontes nos dias de hoje, apesar de mudarem de significado.

\section{A Coleção}

A coleção de cartas da Dracomania compõe uma série de quarenta e duas unidades, sendo trinta e duas delas comuns e dez especiais, ilustradas com imagens que remetem à Idade Média imaginada (medievalidade). Ela foi vendida dentro de salgadinhos da Elma Chips ${ }^{6}$ no Brasil em 2008, fazendo parte de uma tradição da empresa de incluir brindes em seus produtos como elementos estratégicos de persuasão utilizados para conquistar consumidores potenciais, tradição que remete à década de 1980, quando começou com

\footnotetext{
${ }^{6}$ A Elma Chips, empresa estadunidense fundada em 1974 e pertencente à PepsiCo, veiculava os brindes nos salgadinhos Cheetos, Fantangos, Ruffles e Doritos.
} 


\section{artigos}

O mundo medieval no Brasil do século XXI visto através da série de cartas

colecionáveis Dracomania

figurinhas de eventos esportivos, passando pelos anos de 1990 com os "tazos" de metal ilustrados com imagens de desenhos televisivos populares.

De baixo custo, os saquinhos coloridos de chips, em seus diversos formatos e sabores, têm sido um atrativo às crianças desde o seu surgimento no Brasil. Para além do universo plástico construído em volta do produto, a satisfação no ato de consumo do chips parece estar diretamente ligada à surpresa em seu interior: brindes atraentes que convidam à interação e à experimentação do produto (CORRÊA et al, 2014).

Os cartões, ou cards, como popularmente conhecidos, têm em sua face um formato retangular vertical (figura 1), tendo no verso todos a mesma representação de um dragão verde com o nome da coleção e a marca do produto (figura 2), produzindo uma imagem horizontal.
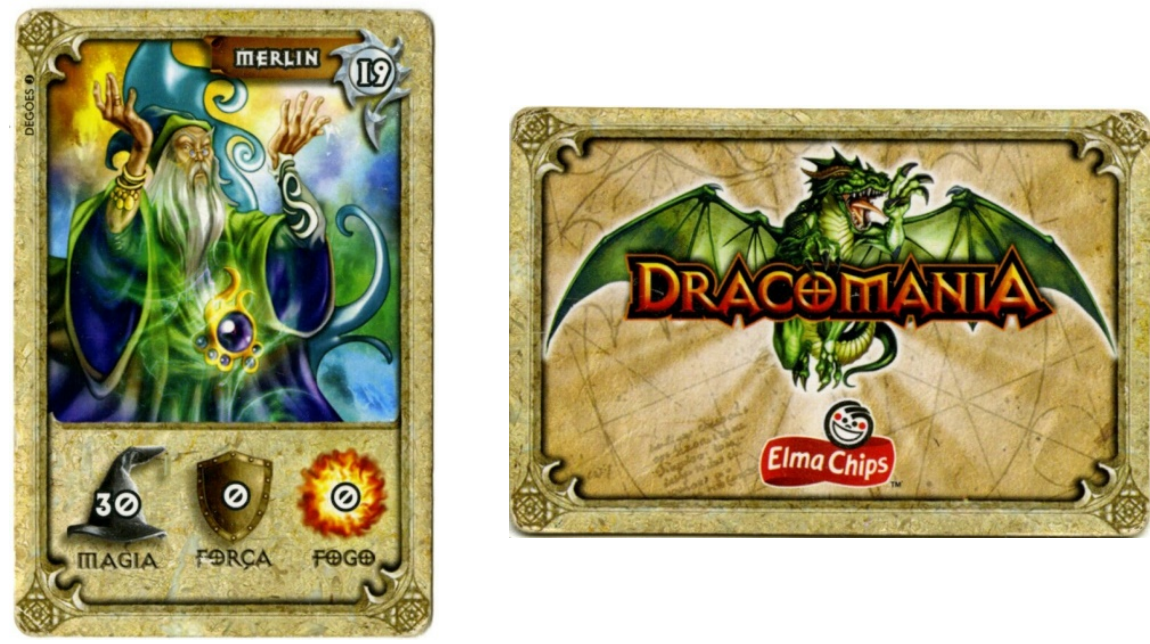

Imagem 1: a face/ Imagem 2: o verso

Eles foram vendidos dentro de um envelope plástico na parte interna do salgadinho. Desta forma, o consumidor não sabia qual card adquiriria quando comprava o produto, fazendo com que fosse impossível completar a coleção sem repetições e com que o colecionador interessado em completá-la tivesse que consumir muito mais salgadinhos do que o número de cards, visto que as trocas, muito comuns no campo dos cards, eram um 


\section{artigos}

\section{Giovanne Santos de Sousa}

recurso para que se pudesse completar a coleção mais rápido, porém era um recurso limitado caso o colecionador não participasse de uma rede.

Dentre os trinta e dois cards comuns se percebe que foi dado um grande destaque aos dragões, que representam dez unidades, sendo os primeiros na ordem numérica, e que dão nome à coleção. O termo Dracomania é uma justaposição das palavras draco, derivada "drakon" que no grego significa grandes serpentes, e mania, que remete a hábito e coleção.

Por conta de os cards especiais serem cópias metalizadas destes dez dragões (figuras 3 e 4), neste trabalho nos centraremos apenas nos trinta e dois comuns. Entretanto, é importante ressaltar que a produção destes dez cards especiais tem pelo menos dois aspectos relevantes: o fato de ser mais um recurso mercadológico da empresa para conseguir embutir um valor maior ao produto e com isso elevar os lucros provenientes da coleção - coleção esta que passa a valer mais do que o próprio produto - e a forma como a venda dos cards especiais em salgadinhos mais caros se torna um empecilho para que colecionadores de baixa rendam completem sua coleção, pois, além de serem menos numéricos, são mais caros, custando de três a quatro vezes o valor do salgadinho comum, que em 2008 custava em média $\mathrm{R} \$ 1,20$.
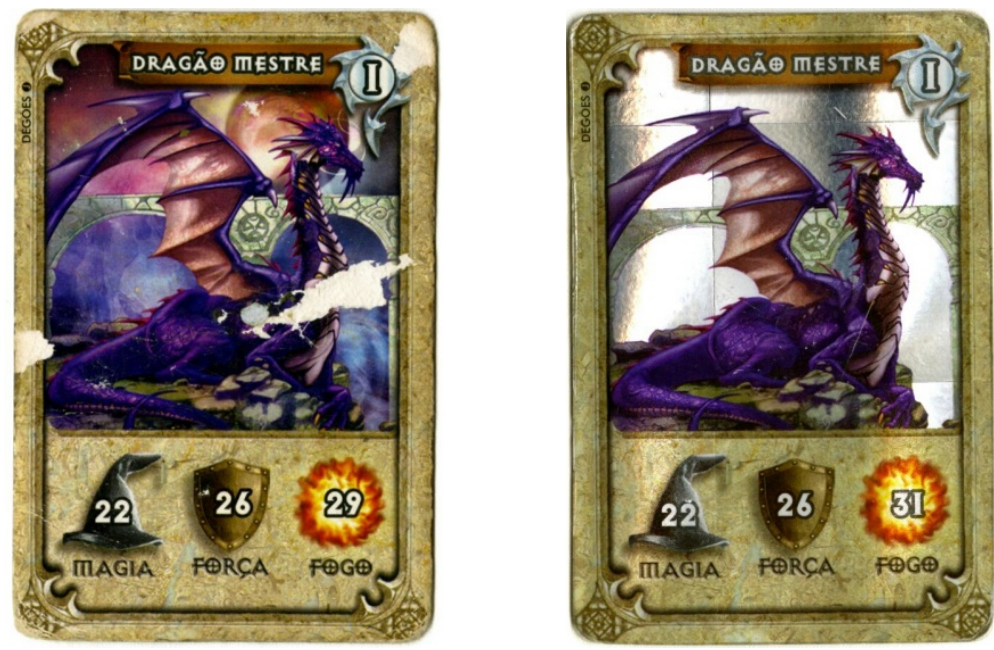

Imagem 3: card comum (danificado) / Imagem 4: card especial 


\section{artigos}

O mundo medieval no Brasil do século XXI visto através da série de cartas colecionáveis Dracomania

Os jogos de cartas, existentes desde pelo menos o século X a.C. na China, refletem, como todo objeto da cultura material, aspectos da sociedade que o produziu. Tendo chegado na Europa durante a Idade Média eles auxiliaram a manutenção do imaginário cultural medieval compartilhando ilustrações de criaturas fantásticas (OTTATI; FREITAS FILHO, 2017, p. 155). Esta tradição dos jogos de cartas culmina nos anos de 1970 numa categoria de jogos conhecidos como RPG (Roleplaying Game), onde os jogadores enfrentam criaturas e seres fantásticos diversos criados num universo mágico que muitas vezes tem referências no imaginário medieval e na Idade Média sonhada hoje.

Dentro deste universo cada ser tem atributos específicos, que lhe conferem habilidades próprias e fazem do jogo uma competição de poderes. Por essa razão cada card da coleção tem suas habilidades distribuídas em três elementos de poder: magia, força e fogo, representados numericamente por números que vão do 0 ao 31, e a competição se desenvolve com dois ou mais jogadores criando um deck (depósito de cartas) que após embaralhado é organizado e colocado com a face das figuras voltadas para baixo, de forma que possibilite ao jogador pegar a carta de cima sem saber qual é e sem ver as de baixo.

Quando cada jogador pegar sua carta, um é responsável por escolher qual será o poder determinante e vence a rodada quem possuir uma criatura com o número mais alto deste poder. Este vencedor recolhe as cartas do ou dos vencidos, as separa, e outra rodada é iniciada com outro competidor escolhendo o poder determinante. No final da partida, quando todas as cartas do deck já tiverem entrado em batalha, vence o jogador que tiver mais criaturas. Não é necessária a coleção completa para que se jogue e não há especificação de regras por parte da Elma Chips que indique um número ideal de cartas ou de jogadores para a partida.

Este modelo de jogo, de funcionamento muito simples se comparado aos jogos clássicos de RPG como o famoso Dungeons \& Dragons, constava na embalagem dos salgadinhos. Não era desejável para a Elma Chips produzir um jogo mais complexo, que 


\section{artigos}

\section{Giovanne Santos de Sousa}

exigiria mais cartas, em razão da dificuldade de compreensão por parte dos consumidores que tal mudança poderia gerar e por acreditarem que uma parcela considerável dos consumidores não investiria no produto por não verem possibilidades de conseguir todos os cards caso a coleção fosse muito extensa.

\section{Dracomania e o Revivalismo Medieval}

A coleção de cards Dracomania reúne representações de seres que podem ser divididas em três categorias, usando-se o critério da forma como as imagens foram produzidas e as figuras nelas desenhadas: a dos animais imaginários, a das criaturas humanas e a dos seres antropomórficos. ${ }^{7}$

\section{Animais Imaginários}

Na primeira categoria, a dos animais imaginários, temos a destacada série dos dez dragões, que são, na sequência numérica: Dragão Mestre, Dragão Dourado, Dragão Prateado, Dragão Bronze, Dragão Cobre, Dragão Branco, Dragão Negro, Dragão Vermelho, Dragão Azul e Dragão Verde.

O primeiro dragão, que é o número um justamente por ser o mestre, é desenhado com o corpo de lado e a cabeça de perfil (figuras 3 e 4), onde pode ser vista uma barba, traço comumente associado na cultura pop, em filmes, séries e livros, a mestres orientais. Os quatro dragões que se seguem são nomeados de acordo com metais, em ordem de preciosidade, e os cincos últimos têm seus nomes associados a cores.

As imagens dos dez dragões estão de acordo com as mais comuns representações atuais da criatura: um ser imenso, de aspecto reptiliano, similar a uma serpente ou a um lagarto, com hálito de fogo e poderes sobrenaturais (SENRA; OTTATI, 2017, p. 179). Estão também de acordo com as definições presentes em bestiários medievias como o de

\footnotetext{
7 "Animais Imaginários" e "Seres Antropomórficos" são categorais usadas por Le Goff em seu "Inventário do Maravilhoso Medieval" (LE GOFF, p. 32-33, 1983).
} 


\section{artigos}

O mundo medieval no Brasil do século XXI visto através da série de cartas colecionáveis Dracomania

Aberdeen, onde se lê que "o dragão é a maior das serpentes e das criaturas vidas da Terra. [...] Ele é a mais monstruosa serpente de todas" (ABERDEEN BESTIARY, folio 65v, 66r, tradução nossa)..$^{8}$

A presença destas criaturas em bestiários medievais demonstra seu caráter de veracidade na consciência coletiva da Idade Média, e o fato de ser dado tanto destaque aos dragões na coleção é muito sintomático do caráter de medievalidade. Estes seres, que estão presentes na consciência coletiva dos habitantes das terras brasileiras desde a chegada dos primeiros viajantes no século XVI (PALAZZO, 2007, p. 9), estão intensamente intrincados no imaginário medieval, apesar de não terem origem europeia, participando de lendas e sendo tidos como seres reais, e estão presentes na imagem criada de Idade Média de forma tão marcante que hoje é difícil encontrar produtos da ficção ambientados em um universo com características ditas medievais que não tenha a presença de destas criaturas.

Os outros dois seres que compõem essa categoria dos animais imaginários são o Pegasus e o Unicórnio. O primeiro deles é um ser de origem grega, presente em histórias da Antiguidade e pouco presente em lendas e códices medievais, tendo sido retomado nos séculos XVIII e XIX por autores como Henry Wadsworth Longfellow e Friedrich Schiller, além de servir de tema para ilustrações de Walter Crane, como indica Thomas Bulfinch em sua obra de referência, “O Livro de Outro da Mitologia” (BULFINCH, 2002, p. 153).

Pegasus, cavalo alado que segundo a mitologia grega surgiu do sangue de Medusa após ter a cabeça cortada por Perseu, voltou a figurar no imaginário coletivo no mesmo momento em que as lendas medievais são retomadas e revalorizadas, o que contribuiu para uma associação entre o ser e o medievo. Para reforçar esta associação, na coleção Dracomania, Pegasus, que foi representando com as asas abertas e as patas em posições diferentes, o que indica o movimento de voo, têm a seu lado parte da torre de um edifício

\footnotetext{
${ }^{8}$ Original: "The dragon is bigger than all other snakes or all other living things on earth. [...] he is the most monstrous serpent of all".
} 


\section{artigos}

\section{Giovanne Santos de Sousa}

com o cume pontiagudo, associado à arquitetura gótica (figura 5).

Quanto ao unicórnio (figura 6), cujas descrições em geral se baseiam no naturalista romano Plínio que o descreveu como um animal feroz, de corpo semelhante ao de um cavalo, com a cabeça de cervo, patas de elefante, cauda de javali, voz retumbante e um único chifre preto na testa, há farta produção historiográfica que investiga seu sentido no imaginário medieval. Seu mito foi criado na Antiguidade e ressignificado na Idade Média, associando-o a poderes mágicos, visto que seu chifre serviria como antídoto a venenos, muito utilizados no período, e inserido num contexto religioso onde era associado tanto à Virgem Maria quanto a Jesus Cristo, de onde vem sua simbologia andrógena. Usando das palavras de Le Goff, podese dizer que

O unicórnio é um belo exemplo da presença de seres imaginários, em paralelo a personagens históricos ou seres reais, dentre os heróis da Idade Média. O destino do unicórnio, enquanto personagem heroica, ilustra, de um lado, a indiferença que durante muito tempo os homens e mulheres da Idade Média demonstravam com relação à fronteira entre imaginário e realidade e, de outro, a paixão deles por heróis surpreendentes e carregados de simbolismo (LE GOFF, 2009, p. 170).
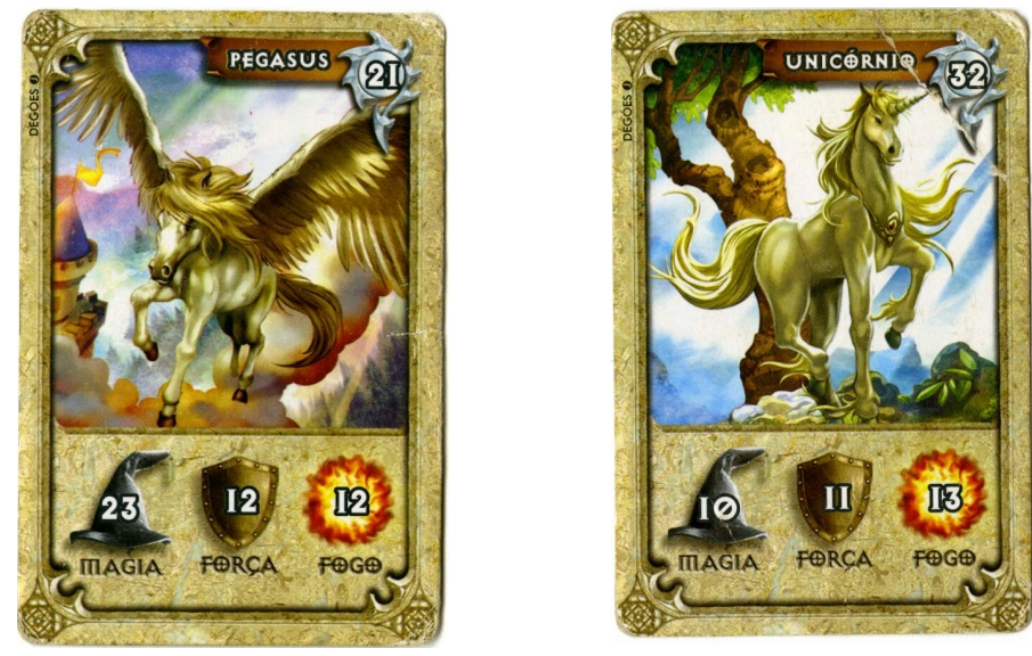

Imagem 5: Pegasus/ Imagem 6: Unicórnio 


\section{artigos}

O mundo medieval no Brasil do século XXI visto através da série de cartas

colecionáveis Dracomania

\section{Criaturas Humanas}

Nesta categoria estão os seres de feições físicas humanas, denominados também como criaturas por estarem representados com características fantasiosas ou seguindo os estereótipos de uma Idade Média imaginada. Esta categoria pode ser subdividida em dois grupos, de acordo com classificações de personagens literários feita por Todorov (1979 apud SILVA, 2017, p. 166), a dos seres de saber e a dos seres de fazer.

Na categoria dos seres de saber estão as criaturas de feição humana com poderes mágicos, que têm essa classificação por agirem como sábios orientando os heróis e não intervindo diretamente na ação. São os detentores do sentido e do saber, e não da força, e por essa característica são os seres com maior numeração no poder magia da coleção.

São cinco os representantes do saber: feiticeira, bruxa, sacerdote, mago e Merlin. Este último é um figura muito presente em obras medievais, tendo suas primeiras menções nas obras de Geoffrey Monmouth, que o coloca ao lado do rei Artur e dos cavaleiros da Távola Redonda. Merlin é um profeta filho de um demônio com uma princesa e, em determinados momentos como no século XIII, aparece como mágico e intérprete de sonhos. É frequentemente revivido em filmes, séries e obras literárias.

Quanto aos outros quatro, chama atenção a forma como são representados com elementos mágicos, um deles com um crânio nas mãos (figura 7) e os outros três com substâncias brilhantes que remetem à magia (figura 8), indicando elementos das tão combatidas religiões pagãs que na Idade Média estavam sendo sublimadas pela Igreja Católica em seu período de institucionalização. 


\section{artigos}

\section{Giovanne Santos de Sousa}
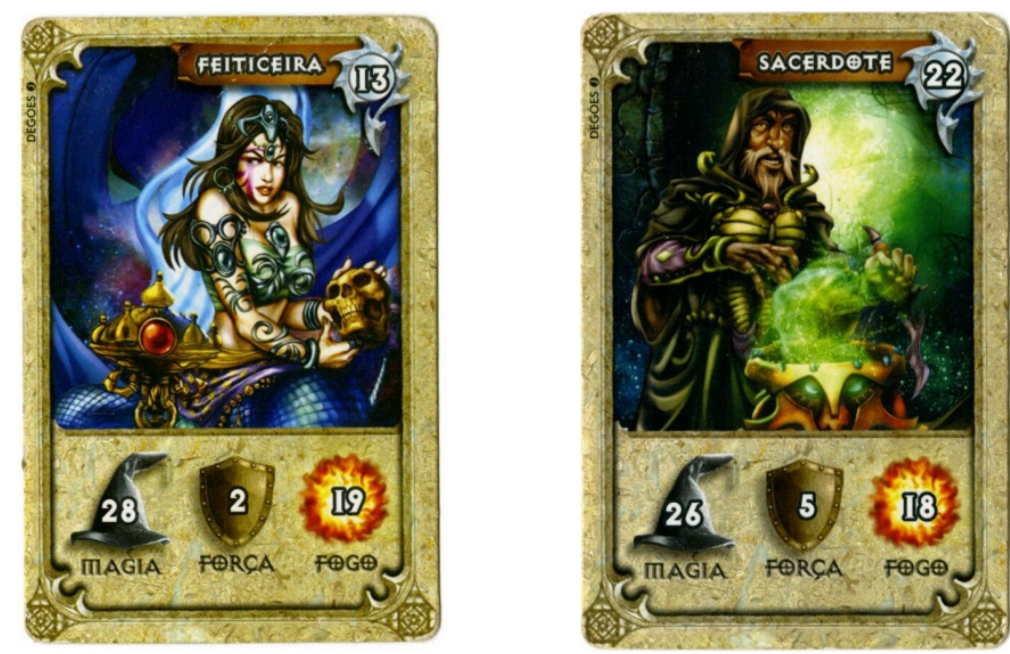

Imagem 7: Feiticeira/Imagem 8: Sacerdote

Outra característica a ser notada é a presença de duas figuras femininas. Com exceção da guerreira, tratada adiante, as representações da bruxa e da feiticeira são as únicas imagens marcadamente femininas na coleção. A existência de poucas figuras femininas no imaginário medieval e na ideia construída de Idade Média, referências destes cards, “corresponde bem a esse período, a essa civilização que Georges Duby chamou de "mâle Moyen Âge" (Idade Média Masculina) (LE GOFF, 2009, p. 17) que reduz a representação feminina nas lendas e mitos. Quanto à concentração das figuras femininas da coleção na categoria de seres humanos mágicos, o que explica é a associação realizada na Idade Média entre mulheres e bruxaria, paganismo e heresia. Citando novamente Le Goff: "A história das heresias é, sob muitos aspectos, uma história da mulher na sociedade e na religião" (Ibid, p. 191).

No grupo dos seres do fazer, aqueles que lutam em batalhas, temos o cavaleiro, a guerreira, o guerreiro, o herói, o bárbaro, o viking e o elfo, sendo que destes o único que destoa da imagem criada de Idade Média é o guerreiro, vestido com trajes leves, peito aberto, sem armadura, vestimenta contrastante às pesadas armaduras associadas à Idade Média.

Diferente do guerreiro, o cavaleiro e o herói vestem armaduras que cobrem todo o corpo, ambos possuem um escudo e uma arma de ataque, sendo a do herói uma espada, arma símbolo do 


\section{artigos}

O mundo medieval no Brasil do século XXI visto através da série de cartas colecionáveis Dracomania

lutador medieval, associada à virtude, bravura e poder, possuindo nas histórias medievais uma relação afetiva com aquele que a maneja, como nas histórias de Sigfried e sua espada Balmuq, Carlos Magno e sua Joyeuse e o Rei Artur com a Escalibur (AMIM, 2017, p. 24).

Quanto ao cavaleiro, apesar da dificuldade de distinguir o mito do real, é consenso de que tem esse nome por lutar montado em um cavalo. Na representação feita pela Elma Chips, o animal tem um grande destaque, sendo proporcionalmente muito maior do que um cavalo comum (Figura 09). Para lutar na montaria, o cavaleiro deve possuir uma arma de longo alcance, e por isso maneja uma lança ao invés da espada.

Outro ser deste grupo, a guerreira, traz novamente a figura feminina. Ela é representada como uma figura forte que, apesar de não ser diretamente associada à bruxaria, pode ser aproximada ao paganismo por portar armas e vestimenta distintas daquelas observadas em representações de cavaleiros cristãos.

No card a guerreira é representada com um elmo com chifres, objeto inexiste segundo a arqueologia, portando como armas um escudo e um machado, o que a diferencia de um cristão portador de espada. Veste roupas curtas, deixando visíveis barriga e pernas e monta uma figura animal fantasiosa, que lembra um rinoceronte, mas tem pele escamosa. (Figura 10).
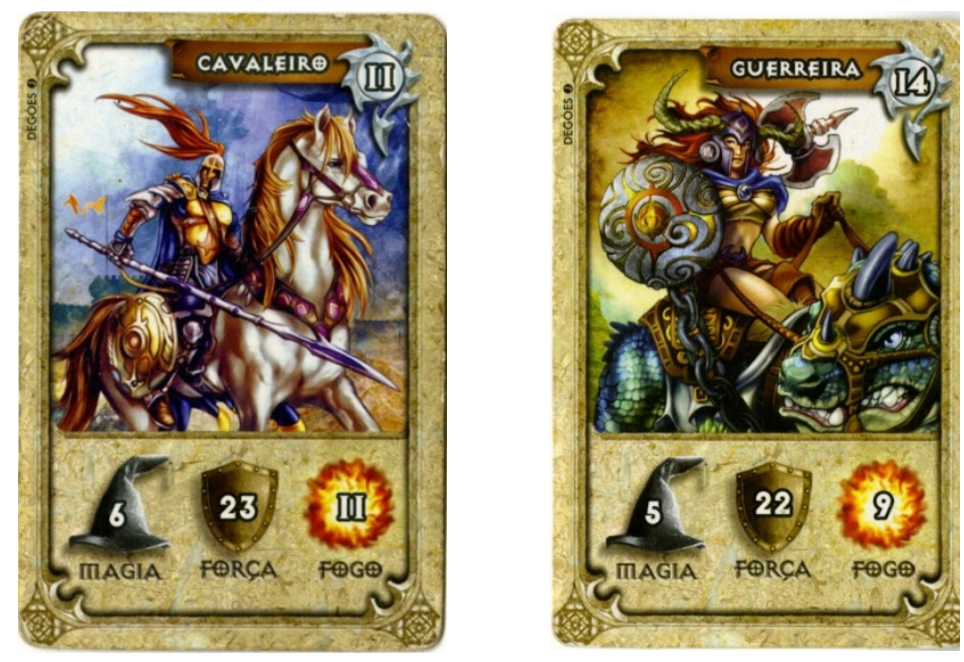

Imagem 9: Cavaleiro/Imagem 10: Guerreira 


\section{artigos}

\section{Giovanne Santos de Sousa}

Tão reproduzido na cultura pop atual quanto os cavaleiros e heróis, este último que por sinal assumiu hoje um significado genérico que representa uma grande classe de guerreiros, é o viking. O grupo histórico tem sua representação constantemente alterada e atualizada para os padrões da medievalidade, sendo sempre muito musculoso e tendo entre seus adereços asas no capacete, criação do século XIX que não possui nenhuma evidência arqueológica (LANGER, 2002, p. 86) (Figura 11).

O viking, historicamente enquadrado no conjunto dos povos chamados "bárbaros", aqui tem representação própria, sendo separado da representação estereotipada do bárbaro, que na coleção é um indivíduo musculoso, com barba e longo cabelo, brincos, portando uma arma que não a civilizada espada, para denotar seu caráter de inferioridade cultural (figura 12). Tanto a imagem do Viking quanto a do Bárbaro demonstram a persistência de imagens construídas sem embasamento histórico que formam o imaginário de tal forma a não serem dissociadas da História. São, nos dizeres de Elias Tomé Saliba, as "imagens canônicas" (1999 apud LANGER, 2002, p. 85).
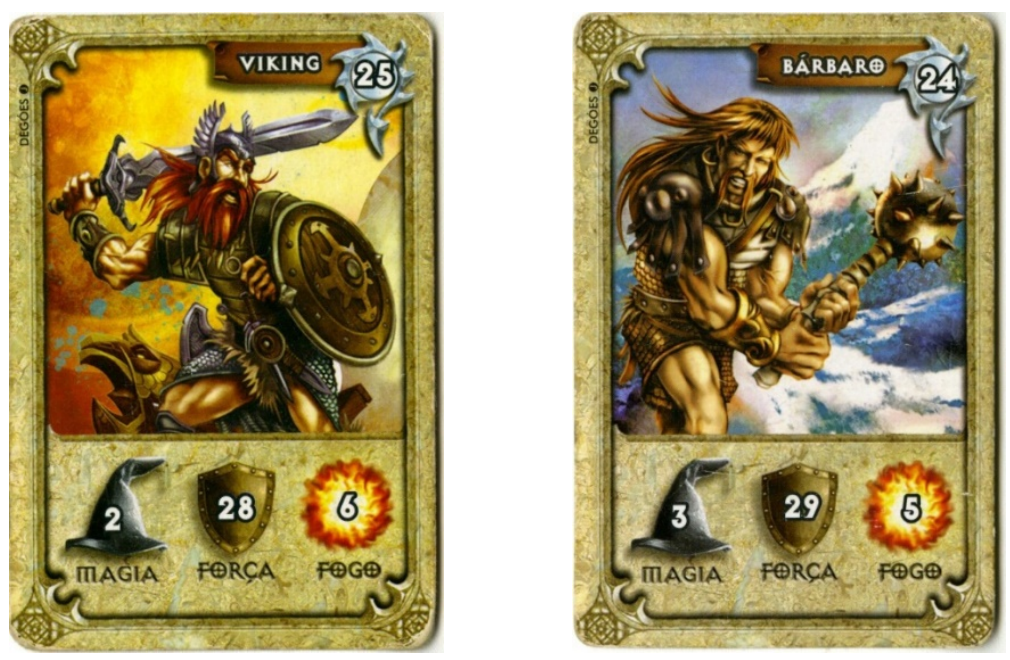

Imagem 11: Viking/ Imagem 12: Bárbaro

Há ainda um elemento da cultura nórdica e celta, o elfo, representado como um ser de 


\section{artigos}

O mundo medieval no Brasil do século XXI visto através da série de cartas colecionáveis Dracomania

feições humanas em meio a árvores, o que indica ser um habitante de florestas, portando um arco-e-flecha, arma que, como outras já tratadas, é tida como símbolo cultural de inferioridade em relação à civilização cristã e suas espadas (LE GOFF, 1983, p. 119). A representação deste elfo está de acordo com as realizadas por Tolkien em suas obras (figura 13), que depois viraram as premiadas trilogias de "O Senhor dos Anéis" e "O Hobbit", o que denota a importância deste autor como fonte de referências.

\section{Seres Antropomórficos}

Nesta terceira e última categoria estão os seres que misturam aspectos humanos com características fantasiosas em sua aparência física, constituindo um grupo de oito criaturas: colosso, gigante de lava, ogro, anjo, lobisomem, sombra, esqueleto e múmia. Os dois primeiros, colosso e gigante de lava, remetem ao imaginário sobre gigantes, muito comum da Antiguidade à Idade Média (WOORTMANN, 2005, p. 280), porém, por terem características peculiares, um tendo seu corpo composto por rochas e o outro por fogo, se percebe que o mito antigo e medieval do gigante passou por ressignificações para que as criaturas fossem representadas como o foram pela coleção.

Quanto ao ogro, ser presente na mitologia clássica e nórdica, hoje muito associado à Idade Média sobretudo em razão dos contos infantis de Charles Perrault escritos entre o século XVII e XVIII, é um ser de grandes dimensões famoso por ter um intelecto pouco desenvolvido e comer carne humana. Sua figura é tão presente que, não por acaso, Marc Bloch, um dos maiores medievalistas franceses, usou a figura desta criatura para cunhar uma das mais famosas frases da historiografia ocidental, a respeito do ofício do historiador, a saber: "Já o bom historiador se parece com o ogro da lenda. Onde fareja carne humana, sabe que ali esta a sua caça" (BLOCH, 2001, p. 54).

Dentre os seres da categoria dos antropomórficos, talvez o mais presente em produções culturais da atualidade seja o lobisomem, criatura existente em diversas culturas, 


\section{artigos}

\section{Giovanne Santos de Sousa}

como a grega, a escandinava e a brasileira, e que dificilmente se ausenta das produções de temática medieval. Segundo Le Goff em seu inventário do maravilhoso medieval, ele é classificado com um ser que se usa da metamorfose e que tem como função a contestação da ideologia cristã (LE GOFF, 2009, p. 36).

Em oposição ao lobisomem, ser de contestação da ideologia cristã, há uma criatura que reforça a ideia de força da religião institucionalizada, que é o anjo, ser bíblico que, no contexto das cruzadas, tem sua figura evocada como protetor dos combatentes. Pode-se inferir que por essa razão o anjo aqui retratado tenha uma representação masculina e musculosa, simbolizando poder e dominação (figura 14).
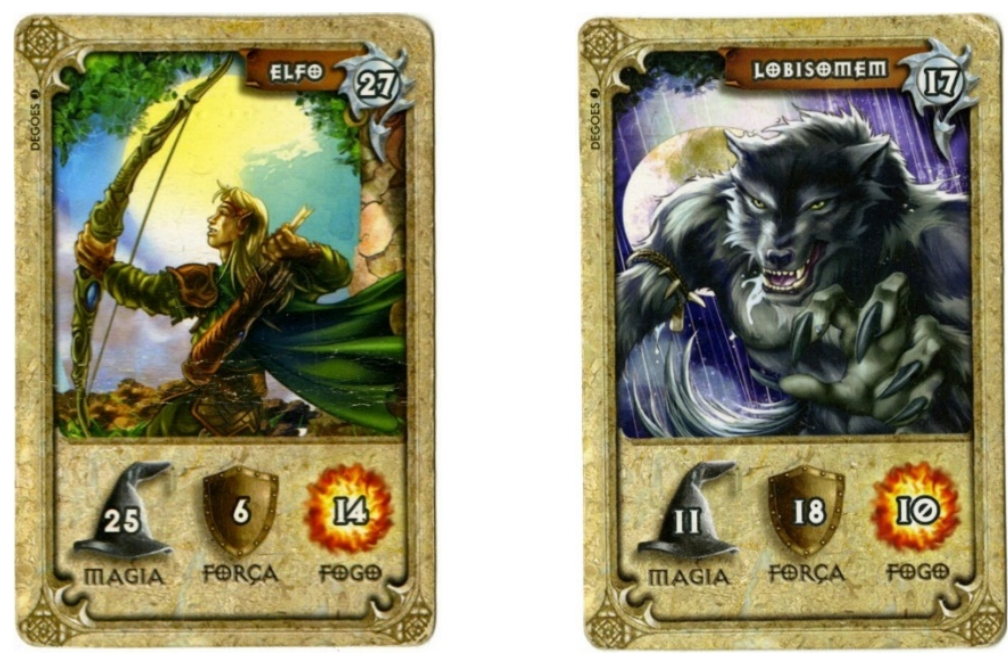

Imagem 13: Elfo/ Imagem 14: Lobisomem

Quanto às três criaturas restantes: a sombra, o esqueleto e a múmia, temos um quadro de poucas referências no imaginário medieval. Sobre a sombra, não foi encontrada nenhuma referência bibliográfica quando da elaboração deste artigo, porém, é curioso notar, ela está representada em uma mundialmente famosa produção cultural da atualidade: a série de livros "As Crônicas do Gelo e do Fogo", e a série televisiva Game of Thrones, baseada nas obras. No que se refere ao esqueleto e à múmia, estas criaturas são mais presentes em obras que remetem ao imaginário da antiguidade, associados ao contexto do Egito Antigo, do 


\section{artigos}

O mundo medieval no Brasil do século XXI visto através da série de cartas colecionáveis Dracomania

que ao do mundo medieval, podendo-se concluir, portanto, que estão deslocados nesta coleção.

\section{Conclusão}

Sabendo que a análise pormenorizada de cada uma das trinta e duas cartas seria impossível, e indesejável, no espaço deste artigo, o que se buscou foi por meio da coleção como um todo ilustrar a forma como no Brasil, país que não viveu diretamente a Idade Média Ocidental, o imaginário medieval sobrevive e suas representações são revividas com frequência em diversos meios.

Filmes, livros, séries e jogos, como neste caso, têm na Idade Média um fértil campo de referências para criar universos e seres que transitam entre a sociedade medieval histórica e uma criação fantasiosa, abundante em elementos maravilhosos deste período, e a utilização destas mídias oferece grande potencial no Ensino de História, pois diversas problemáticas podem ser estabelecidas a partir deste material.

Questões como: com qual período estes cards se relacionam, quais lembranças surgem à mente quando eles são vistos, quais mídias (filmes, séries, livros, jogos) seguem a mesma temática e ambiente podem ser utilizadas pelo professor de História como ponto de partida para atividades que busquem fazer com que estudantes compreendam o significado da confecção destes cards em nossa sociedade, comparem esta Idade Média construída com aquela estudada em seus livros e aulas e reflitam sobre a forma como mitos e lendas se misturam com a História no imaginário coletivo.

Não sendo o papel do professor e historiador julgar se os processos de apropriação de temas do imaginário medieval e da criação de uma nova e sonhada Idade Média são benéficos ou não para a compreensão histórica, o que lhe cabe é compreender as formas e razões destes processos, para por meio desses estudos levantar elementos que auxiliem na compreensão da sociedade medieval, por meio de seu imaginário, e da sociedade atual que o revive e (re)cria. 


\section{artigos}

\section{Giovanne Santos de Sousa}

\section{Referências bibliográficas}

ABERDEEN BESTIARY. Special Colections Centre, University Library, Aberdeen. Disponível em: $<$ https://www.abdn.ac.uk/bestiary/ms24/f65v>.

AMARAL, Ronaldo. O Medievalismo no Brasil. História Unisinos, São Leopoldo, v. 15, n. 3, p. 446-452, set./dez. 2011.

AMIM, Mônica. "A Idade Média: um Tempo de Fazer Cristão". Revista ComparArte, Rio de Janeiro, v. 1, n. 1, p. 116-141, jan./jun. 2017.

BLOCH, Marc. Apologia da História ou O Oficio de Historiador. Rio de Janeiro: Zahar, 2001.

BULFINCH, Thomas. O livro de ouro da mitologia (a idade da fábula): histórias de deuses e heróis. Tradução de David Jardim Júnior. Rio de janeiro, 26ª Ediouro Publicações, 2002.

CORRÊA, Laura Guimarães; SALGADO, Tiago Barcelos Pereira; CASTRO, Rebeca Heringer Lisboa de. É impossível comer um só? Publicidade, embalagem e conteúdo dos salgadinhos Elma Chips. Signos do Consumo, São Paulo, v. 6, n. 1, p. 56-70, jul. 2014.

FRANCO JÚNIOR, Hilário. “Raízes Medievais do Brasil”. REVISTA USP, São Paulo, n.78, p. 80-104, jun./ago. 2008.

LANGER, Johnni. "Os vikings e o estereótipo do bárbaro no ensino de história". História \& Ensino, Londrina, v. 8, out. 2002.

. "O ensino de História Medieval pelos quadrinhos". História, imagem e narrativas, Rio de Janeiro, n 10, abr. 2010.

LE GOFF, Jacques. Heróis e Maravilhas da Idade Média. Rio de Janeiro: Vozes, 2009.

. O Imaginário Medieval. Lisboa: Editorial Estampa, 1994.

. O Maravilhoso e o Quotidiano no Ocidente Medieval. Lisboa: Edições 70, 1983.

MACEDO, José Rivair. Sobre a Idade Média Residual no Brasil. A Idade Média Portuguesa e o Brasil: reminiscências, transformações, ressignificações. Porto Alegre: Vidráguas, 2011.

MENESES, Ulpiano T. Bezerra de. "Do teatro da memória ao laboratório da História: a exposição museológica e o conhecimento histórico". Anais do Museu Paulista, São Paulo, v.2 p. 9-42 jan./dez. 1994.

OLIVEIRA, Beatriz dos Santos; FREITAS FILHO, Mario Marcio Felix. "A Idade Média no Cinema: uma (Re)Visão do Imaginário Ocidental". Revista ComparArte, Rio de Janeiro, v. 1, n. 1, p. $142-$ 150, jan./jun. 2017.

OTTATI, Rafael Delgado Gomes; FREITAS FILHO, Mario Marcio. “Somos Bárbaros, Guerreiros, Magos e Feiticeiros: A Idade Média Revisitada nos Games". Revista ComparArte, Rio de Janeiro, v. 1, n. 1, p. 151-161, jan./jun. 2017.

PALAZZO, Carmen Lícia. Visões francesas do Brasil: permanências medievais nos relatos da modernidade. Univ. FACE, Brasília, v. 4, n. 1/2, jan./dez. 2007. 


\section{artigos}

O mundo medieval no Brasil do século XXI visto através da série de cartas colecionáveis Dracomania

POBLADOR MUGA, María Pilar. El neogótico y lo neomedieval: nostalgias del pasado en la era de la industrialización. El recurso a lo simbólico: reflexiones sobre el gusto II, Zaragoza, p. 119144, 2014.

SENRA, Flavio Pereira; OTTATI, Rafael. "Música Medieval Contemporânea?" Revista ComparArte, Rio de Janeiro, v. 1, n. 1, p. 174-191, jan./jun. 2017.

SILVA, Renan Cardoso Pinho da. "A Representação do Imaginário Medieval nas obras de Epic Fantasy: o caso de As Crônicas de Gelo e Fogo." Revista ComparArte, Rio de Janeiro, v. 1, n. 1, p. 162-173, jan./jun. 2017.

WOORTMANN, Klass. "O selvagem na 'gesta Dei': história e alteridade no pensamento medieval". Rev. Bras. Hist., São Paulo, v. 25, n. 50, jul./dez. 2005.

\section{Imagens}

Imagem 1: COLEÇÃO DRACOMANIA. Carta no 19 comum, Merlin (frente). 2008. Imagem 2: COLEÇÃO DRACOMANIA. Carta no 19 comum, Merlin (verso). 2008. Imagem 3: COLEÇÃO DRACOMANIA. Carta nº 1 comum, Dragão Mestre. 2008. Imagem 4: COLEÇÃO DRACOMANIA. Carta no 1 especial, Dragão Mestre. 2008. Imagem 5: COLEÇÃO DRACOMANIA. Carta nº 21 comum, Pegasus. 2008. Imagem 6: COLEÇÃO DRACOMANIA. Carta n 32 comum, Unicórnio. 2008. Imagem 7: COLEÇÃO DRACOMANIA. Carta n 13 comum, Feiticeira. 2008. Imagem 8: COLEÇÃO DRACOMANIA. Carta n 22 comum, Sacerdote. 2008. Imagem 9: COLEÇÃO DRACOMANIA. Carta n 11 comum, Cavaleiro. 2008. Imagem 10: COLEÇÃO DRACOMANIA. Carta nº 14 comum, Guerreira. 2008. Imagem 11: COLEÇÃO DRACOMANIA. Carta n 25 comum, Viking. 2008. Imagem 12: COLEÇÃO DRACOMANIA. Carta n 24 comum, Bárbaro. 2008. Imagem 13: COLEÇÃO DRACOMANIA. Carta nº 27 comum, Elfo. 2008. Imagem 14: COLEÇÃO DRACOMANIA. Carta no 17 comum, Lobisomem. 2008. 